\title{
Tips for Co-authoring Papers: How to Team Up Without Regrets
}

\author{
Kevin D. Taylor, Russell A. Aubrey, Rick L. Homkes \\ Purdue University - School of Technology
}

\begin{abstract}
This paper investigates successful methods of teaming with colleagues in publishing efforts. The selection of co-authors, starting the writing process, and the delegation of the responsibilities are discussed. The paper recommends that co-authors decide upon all details of the process prior to engaging in partnership. By discussing and deliberating these issues before initiation of the project, co-authors can avoid many problems.

The paper includes the steps and a timetable for creation of a successful paper. These steps are brainstorming, creating the abstract, building the first draft, editing, submitting and presenting the paper. Anecdotal scenarios of both successful and unsuccessful publishing efforts are presented. Past problems encountered with co-authors, such as incompatible writing styles and over commitments, are highlighted. We also cite some disastrous scenarios we have experienced.
\end{abstract}

\section{Choosing a co-author}

After several "successful" and "less than successful" co-authoring efforts, we wanted to share some advice with those considering authoring for the first time. This advice may also apply to seasoned writers. By following the suggestions given, potential disasters and embarrassing situations can be avoided.

Choosing your co-authors may be the result of a discussion, a common interest, an innovative idea, or a collaboration on a project. Upon agreeing to co-author, you and your colleagues generally must make a verbal contract to share equally or unequally the labors of the effort. Before entering into the venture, each person must decide if the potential partners will actually perform to the standards set out in the verbal agreement. Simply saying "Let's write a paper" does not get the paper written.

The number of authors depends upon the depth of the subject and the potential ability for contribution to the topic. Too many authors can complicate the writing process and dilute the credit allocated. Senior faculty should help junior faculty in initiating their publishing experience. This is especially true of recently tenured associate professors. While junior faculty may perform the majority of the work, it is incumbent upon the senior faculty to guide them through the process. 


\section{Planning the work}

Here are the suggested steps required to complete the publishing and presenting process:

The Idea - If you are searching for ideas, brainstorm with your colleagues and read pertinent publications to see what others have done. Assess your own efforts and interests with potential co-authors. Find others in the department with interests that are either similar or congruent. One co-authoring effort resulted from a disagreement between two colleagues that led to a search to see who was right. The search turned into a reference list for a journal article.

The Abstract Submission - The abstract must sell the idea for the paper. It should be brief and clearly define the content of the paper. Despite the rumors, you may write an abstract without actually having the paper completed. However, you should have some good ideas and direction, otherwise your paper might be very brief. The best method is to write the abstract after you have written at least an outline or draft of the paper. The abstract should be written by one of the authors, then revised by the team. Don't let co-authors submit abstracts too freely. Having too many papers to write can be as bad as not having any at all. Submit the abstract ON TIME! Late abstracts typically receive no consideration.

First Draft - It is possible for each author to write separate sections of the first draft, but it is best to work from an outline and have one author compose the draft. Writing separate sections results in choppy transitions between sections. We have tried that, and our proofreader usually writes "new author!" at the breaks. Unless you all write in the same style, one author needs to write the draft for a continuity of voice. If done correctly, this is the lion's share of the effort, and this author will receive the most credit. In addition, this "primary author" will generally be responsible for meeting the publication deadlines.

Revisions - Revisions need to be a joint effort. After writing the draft, the author needs positive criticism. A skim through and a "thumbs up" from the rest of the team contributes nothing to the content of the paper. A lightly proofed paper is destined for rejection or major revision. A poorly written paper will receive higher scrutiny regardless of the content. A paper submitted in draft format for review is an insult to the reviewers and deserves rejection. One example we saw was a very interesting article, but the writing included run-on sentences with parenthetical comments in the middle. It took three readings to determine the point of the article. A regular reader would have skipped the article after the first paragraph.

Submission for Review - Once the team has revised the paper to "final" form, get at least one fresh set of eyes to read it. This will usually flush out any minor problems that the authors might miss. From personal experience, it is embarrassing to discover a typographical error in one of your published papers. Next, submit the paper ON TIME! The deadline could be set by a "call for papers," or on a schedule originally agreed upon by the co-authors. If a target date is not set, the paper may not be written due to higher priorities. Papers received late are subject to review under a limited time schedule. Again, because they are late, they may be more closely scrutinized, or even rejected. 
Reviewers' Comments - Consider review comments very seriously. It is annoying for a reviewer to see an article that he or she reviewed appear in a proceedings with no modifications. Journal articles will never be published without addressing reviewers comments. We recommend sending a revised copy to the moderator noting modifications made in response to review comments. Occasionally, reviewers conflict in opinion, or the changes are not compatible with your own ideas. Report that to the moderator or editor and it should not be a problem. Revisions based upon review comments should be a team effort.

Rejection - Accept rejection professionally. Individual papers may be appropriate for some conferences or journals, but not others. The moderator or editor has the responsibility for the session or journal content. They should reject any paper that does not meet the theme of the session, deviates from the subject of the accepted abstract, or receives a rejection from the review process. The author should contact the moderator to see if any of the effort can be salvaged. Use the review comments to improve the paper and resubmit it elsewhere.

The Final Submission - Once the entire team is satisfied with the article, it should be proofread by a non-author. If possible, utilize someone who has not read any of the drafts. Submission of papers has changed dramatically over the past several years. We no longer have to print on mats and cut and paste. However, formatting standards are becoming more complicated, and electronic submission adds a new twist to the process. In some cases getting the article formatted and submitted is second in difficulty only to the initial draft. Once again, keep to the deadlines and submit the final paper ON TIME!

The Presentation - Several months pass between submission of the paper and the presentation. You have moved on to the next project, when suddenly you realize that you have to make a presentation. The team can decide to share this task, or in order to even out the work load, have one person do the presentation. In the latter case, the person making the presentation should write it to allow continuity in voicing.

Most institutions have short courses on making effective presentations. Everyone should participate in one of these courses not only for improving their paper presentation skills, but also to enhance their teaching. If a course is not available on your campus, consult one of the many "how to" books on the subject. (See bibliography.)

Rehearse the presentation in front of the entire team. If this is not possible, find a substitute audience. For best results, rehearse the presentation two to four times with a day between each sitting. Too much practice can make the presenter go too fast, or lose enthusiasm in the subject. Videotape your presentation and watch it at home. Your family may get a laugh from it! You may spot annoying mannerisms that you had no idea you were doing. In any case, BE PREPARED. As an audience member, it is insulting to have a presenter who has excuses about the quality of a talk. It is like the student who says his hard drive crashed as he was starting his ten page report for you this morning. Finalize the presentation before you leave for the conference. Select a presentation technology that will work smoothly in the time allotted. If you plan a computer presentation, have transparency backups. Don't try the audience's patience by running back to your car for the right disk or computer cable. 


\section{Giving Credit Where Credit is Due}

At some institutions, the principal authors' names appear with an asterisk $\left(^{*}\right)$ on the promotion document. If you operate under a similar scheme, decide at the onset how this will be handled. If the distribution of work changes during the course of the project, this needs to be re-negotiated. For example, if one author plans to present the paper and the other to compose the first draft, they might share the authorship equally. However, if the presenter discovers a travel conflict, the other author should receive principal authorship if he or she presents the paper and composes the draft. Teams need to realize that this may happen and avoid conflict when the re-negotiation of credit takes place. In some cases the authors names are simply listed alphabetically. This seemingly minor detail must be agreed upon in advance.

\section{What Doesn't Work}

The worst thing to do to an excellent paper is to turn it into a terrible presentation. While attending a conference, one of our authors found interest in an abstract appearing in the proceedings. At the session, the presenter started by making the excuse that he did not have time to make appropriate overheads for the presentation. He then put up an overhead of the first page of the paper (in 10 point font), which he then read to the audience. One year later at a different conference, the same author presented another paper the same way. Fortunately, the listener selected a seat that allowed an early escape.

Newly united co-authors should expend a great deal of effort working out specific plans for draft revisions and third party comments prior to submission for review. One situation occurred where "author A" submitted a joint paper prematurely. He failed to follow "author B's" suggestion that the paper be proofread by a non-author before submission. The paper was poorly written and contained unusual grammatical construction. One reviewer refused to read past the first page. The other reviewers suggested moderate revision. "Author B" performed a major rewrite with minimal help from his collaborator. Situations like these can be avoided by following a good set of work rules agreed to by both parties.

\section{Conclusion}

Good papers result from careful planning and hard work. The suggested steps for successful paper writing described previously do not guarantee success. However, not following a similar set of directions will guarantee a less than pleasant experience in the collaboration.

During the course of writing this paper, several serious to heated discussions transpired. Without some up-front agreements, it is possible that these discussions would have terminated the effort and the working relationships among the authors. 


\section{Bibliography}

Arrendondo, L. (1991). How to present like a pro. New York: McGraw Hill.

Mager, E. W. (1984). Classroom Presentation Skills Workshop. Carefree, AZ: Mager Associates.

Heinich, R., Molendia, M., \& Russell, J. (1993). Instructional Media and the New Technologies of Instruction. Fourth edition. New York, NY: Macmillian.

Presentation Skills for the Classroom Workshop. Center for Instructional Services at Purdue University, 1994.

Antaki, P. J. (1992, April). Designing and Delivering Technical Presentations. Mechanical Engineering, 63-65.

Conroy, C. M., \& Wright, C. R. (1993, May/June). Getting your brain wave to print. Performance \& Instruction, 19-22

Homkes, R. (1996). Writing and publishing your way to tenure. [CD ROM: \papers\2275\227503ms.pdf] 1996 ASEE Annual Conference Proceedings. American Society for Engineering Education, Washington, DC.

\section{Biographical Information}

Kevin D. Taylor is an Assistant Professor of EET at Purdue University at Kokomo. Prior to starting his teaching career in 1987, Mr. Taylor was an IC Design Engineer for Texas Instrument, Inc. He spent the past three summers working at Delco Electronics, Inc. in the areas of IC modeling and electric vehicles. His interests are in teaching IC fabrication.

Russell A. Aubrey is an Associate Professor of EET at Purdue --Anderson. His industrial background includes technical staff assignments with NASA-Langley Research Center, Texas Instruments, Inc. and Seyberts/Anderson Electronics. Current teaching interests are analog and digital electronics. He is a member of ASEE and IEEE.

Rick L. Homkes received his BS degree from Northern Michigan University, and his MS from Central Michigan University. He is an Associate Professor at Purdue -- Kokomo in the Computer Technology Department. Mr. Homkes is taking graduate classes at Purdue and worked the past two summers at Delco Electronics, Inc. coding $\mathrm{C}$ in a prototype test laboratory. 